\title{
Monitoring of Particulate Matter and Analysis of Black Carbon and Some Particle Containing Toxic Trace in the City of Yaoundé, Cameroon
}

\author{
Tchuente Siaka Y.F. ${ }^{1)}{ }^{*}$, Saidou ${ }^{1,2)}$, Yakum N.Y.1), Kenmoe N.X.(1) and Abdourahimi ${ }^{2)}$ \\ ${ }^{1)}$ Nuclear Technology Section, Institute of Geological and Mining Research, P.O. Box 4110 Yaounde, Cameroon \\ ${ }^{2}$ Nuclear Physics Laboratory, Faculty of Science, University of Yaounde I, P.O. Box 812, Yaounde, Cameroon
}

*Corresponding author. Tel: +00237 942632 40, E-mail: siakaf@yahoo.fr

\begin{abstract}
The concentration and composition of particulate matter (PM) in the atmosphere can directly reflect the environmental pollution. The atmospheric pollution in some Cameroonian cities is increasing with the industrial development and urbanization. Air pollution is inherently complex, containing PM of varied size and composition. This PM exists as a dynamic cloud interacting with sunlight and is modified by the meteorology. The reflectometer and the EDXRF spectrometry are applied to determine the concentration of some specific elements at four sites in the city of Yaoundé.

The particular aim of the present work is to put in place data base on air pollution in urban area and elaborate regulations on the emissions issued to industrial and vehicle activities. This study provides an overview of the concentration of black carbon and some specific elements in the air, which have impacts on human health. The measurement was done by distinguishing the size of particle. So that, the particle with aerodynamic diameter between 2.5-10 $\mu \mathrm{m}$ (so-called coarse particle) and aerodynamic diameter $<2.5 \mu \mathrm{m}$ (so-called fine particle) were considered to obtain more information about levels of the inhalable fraction of the location. The results obtained in four locations of the city of Yaoundé show that the black carbon concentration is very considerable, the element sulfur is a major pollutant and the concentration of fine particle is very greater.

The results obtained of fine and coarse filters range from $5-17 \mu \mathrm{g} / \mathrm{m}^{3}$ and $10-18 \mu \mathrm{g} / \mathrm{m}^{3}$ for the black carbon. $\mathrm{S}, \mathrm{Cu}, \mathrm{Zn}, \mathrm{Pb}, \mathrm{Cd}, \mathrm{As}$, Se and $\mathrm{Hg}$ are the specific findings of this work. The pollutants with a greater concentration are $\mathrm{S}, \mathrm{Pb}$, and $\mathrm{Zn}$. These later seem to be non-uniformly, non-regular in some location and high compared to other countries. This work allows us to make a potential relation between pollutants
\end{abstract}

and emission sources. In this framework, some suggestions have been proposed to reduce emissions for an improvement of the air quality in the environment and thus, the one of the city of Yaoundé.

Key words: Black carbon, Trace element, $\mathrm{PM}_{2.5}$, Coarse particles, Reflectometer, EDXRF

\section{INTRODUCTION}

Cameroon located in central Africa has planned to be an emerging country by 2035 . Follow of this, many activities are growing up for increased socio-economic development. The first impact is the urbanization of the most populated cities like the city of Yaoundé, located in the centre of Cameroon, where migration increased over this past decade. Urban air pollution poses significant threat to the human health and the environment. Clean air must be considered to be a basic requirement of human health and well being. Thus, an attention has to be taken on urban air quality because majority of the Cameroonian lives in urban centers and need a cleaner environment. The combination of large populations, industrial emissions, and increases of old vehicles has an influence on the environment which may be particularly severe in a country as reported by Kinyua et al. (2008) and Zhifang et al. (2008).

The first measurement in Yaoundé was carried out within the framework of the Regional African project (RAF 4019) on Air Pollution Monitoring in Urban Areas, funded by the International Atomic Energy Agency (IAEA) through its regional cooperation agreement in Africa. This cooperation initiated the project in year 2008 to assist the member states in collecting and analyzing particulate matter samples. The objective of the project was the building of a local capacity to monitor air quality, determination of key pollutants and sensitize decision makers on the need to have a 
long term air quality management strategy. Nowadays, with some collaboration, we have studied some techniques to sample, analyze, and use resulting data to assess particulate air pollution.

This work is the first experience to apply the learning techniques. The principal objective of this work is to put in place a data base on air pollution by identifying specific key pollutants in the city of Yaoundé and elaborate a regulation on the emissions issued from industrial and vehicle activities. This objective has been achieved thanks to the realization of these specific objectives such as:

- Acquisition of equipment and test.

- Identification of some locations in the city of Yaoundé for the measurement.

- Stationary sampling on different locations.

- Collection of filter, measurement, interpretation and identification of major key pollutants in the city.

- Redaction of a related process by mentioning emission sources for the following works in the country.

The identification of different sampling locations in Yaounde was based on the geographic situations of the city. Several mountains, land and lot of rivers are located in this city. Most of the people are living in the valley where the air is not continuously changing.
Thus, all the emissions from industries, two-strokes motors, vehicles, biomass burning, and soil dusts are accumulated in the environment. These emissions have severe impacts on human health (Pinheiro et al., 2008).

The project RAF 4019 provides data that focus firstly on urban particle concentrations and compositions that affect air quality and significant adverse health effects in the city. The results of this work can be used to assess impacts of air pollution on human health and their potential mitigation by identification and quantitative apportionment of the particulate matter source.

\section{EXPERIMENTAL METHODS}

\section{1 Sampling Sites}

Yaoundé, political capital is located in the central region (Fig. 1). This city is populated due to its facilities to develop activities. So that, in spite of the lack of good road in the city, there is an intense traffic with a mixture of old vehicles and two stroke motors. Industrial is also considered, because some industries inject pollutants into the environment. We can also indicate the use of biomass by most people. We selected four locations for the sampling. The characteristics of these locations are given on Table 1 with each period of sampling and specific remarks.

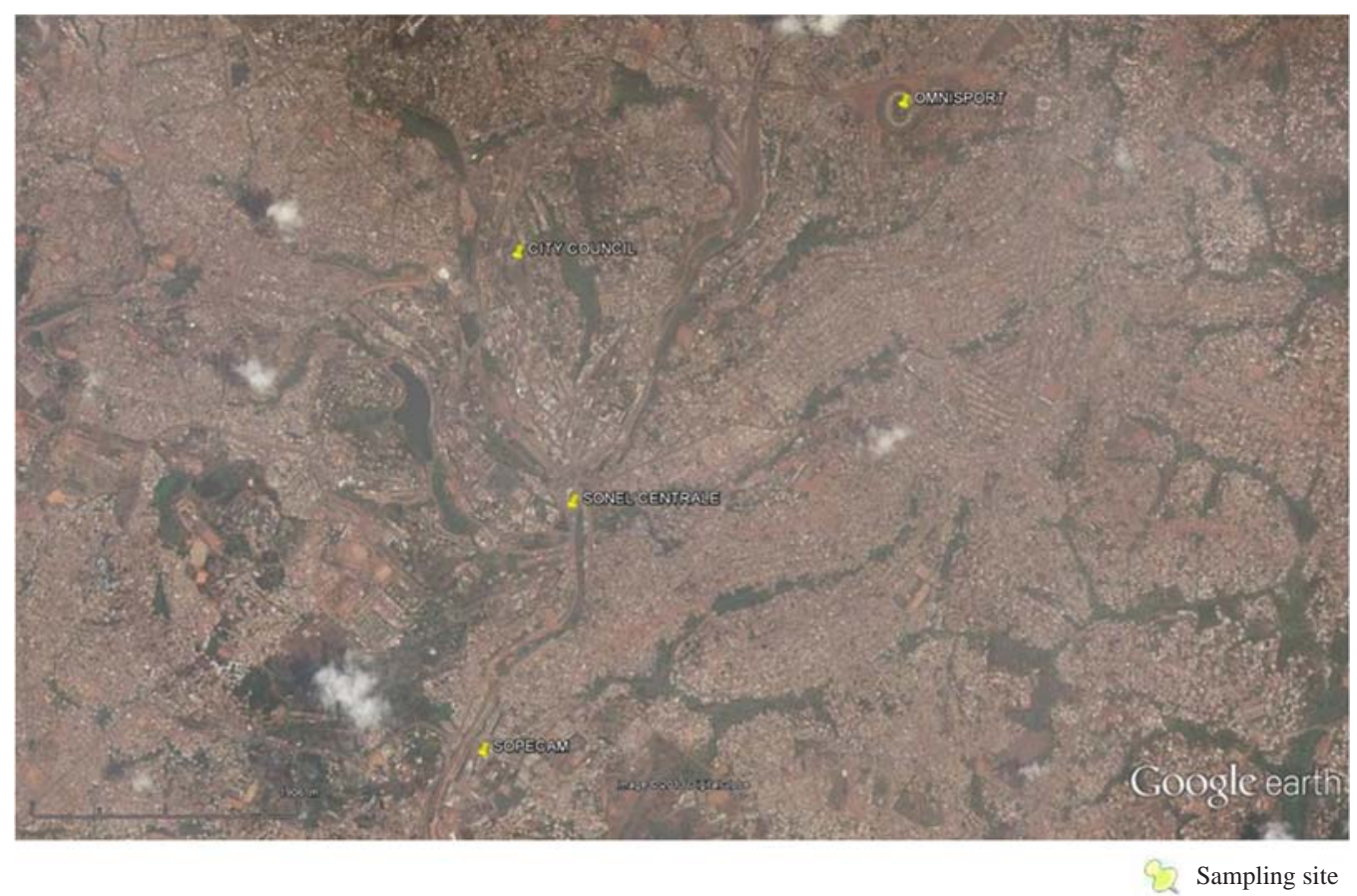

Fig. 1. The sampling sites (CITY COUNCIL, OMNISPORT, SONEL CENTRALE and SOPECAM) are pointed by a yellow peak on the city of Yaoundé map. 
Table 1. Geographic situation of sampling sites, the period of sampling and observation.

\begin{tabular}{|c|c|c|c|c|c|}
\hline Locations & Latitude & Longitude & Start date & End date & Observation \\
\hline City Council & $\mathrm{N}^{\circ} 3^{\circ} 52.497^{\prime}$ & $\mathrm{E} 011^{\circ} 30.997^{\prime}$ & $02 / 11 / 2010$ & $07 / 11 / 2010$ & $\begin{array}{l}\text { Smelting industry, Intense traffic } \\
\text { Biofuels for cooking, Solid waste }\end{array}$ \\
\hline Sonel Centrale & $\mathrm{N}^{\circ} 3^{\circ} 51.559^{\prime}$ & $\mathrm{E} 011^{\circ} 31.239^{\prime}$ & $17 / 11 / 2010$ & $23 / 11 / 2010$ & $\begin{array}{l}\text { Administration Centre, Intense traffic } \\
\text { Solid waste }\end{array}$ \\
\hline Omniport & $\mathrm{N} 03^{\circ} 53^{\prime} 06,94^{\prime \prime}$ & $\mathrm{E} 011^{\circ} 32^{\prime} 26,55^{\prime \prime}$ & 09/11/2010 & $15 / 11 / 2010$ & $\begin{array}{l}\text { Lots of dust, Intense traffic } \\
\text { Biomass burning, Solid waste }\end{array}$ \\
\hline Sopecam & $\mathrm{N}^{\circ} 3^{\circ} 50^{\prime} 36,07^{\prime \prime}$ & $\mathrm{E} 011^{\circ} 30^{\prime} 55,79^{\prime \prime}$ & $25 / 11 / 2010$ & $01 / 12 / 2010$ & $\begin{array}{l}\text { Smelting industry, Biomass burning } \\
\text { Solid waste }\end{array}$ \\
\hline
\end{tabular}

\section{2 Environmental Samples}

Stationary sampling was carried out at four locations chosen in the city with the Gent Stacked Filter Unit (SFU). This equipment consists essentially of two principal parts connected by a cable. The components of the first part are a double (stacked) filter cassette, a black polyethylene container and a red-coloured rain protection. The double filter cassette was employed with two different Nuclepore filters of a diameter of $47 \mathrm{~mm}$ with a pore size of $8 \mu \mathrm{m}$ and $0.4 \mu \mathrm{m}$, operated at a flow rate of $15 \mathrm{lpm}$ for 12 hours (Hopke et al., 1997; Gatebe et al., 1996). Under these conditions, size fractionating of particulate matter occurs so that the former filter collects particulate matter having aerodynamic diameter in the range of $2.5-10 \mu \mathrm{m}$ (so-called "coarse" fraction), while the latter filter collects particle matter with aerodynamic diameter $<2.5 \mu \mathrm{m}$ (so-called "fine" fraction). The second part of this equipment consists of a needle valve to regulate the flow rate, a vacuum gauge, a vacuum pump, rotameter, a time switch and hour meter.

Before the start of each sampling, Nuclepore filter membranes were weighted in air-conditioned laboratory controlled at $68 \%$ relative humidity and $21^{\circ} \mathrm{C}$. The SFU has been cleaned with ethanol to remove any particles, which may have previously embedded inside. Filters were handled with care to avoid any contamination from fingers and heavy metals. The directly recorded information was the volume of air introduced by the pump and average weather parameters such as temperature, humidity and wind direction. The fine and coarse mass concentrations were obtained through gravimetric measurements of Nuclepore filter membranes with a weighting balance (TE 153S, Sartorius).

Collected samples were analyzed using firstly the reflectometer EEL Models 43D (M43D SMOKE STAIN REFLECTOMETER). This type of equipment is the reference instrument to measure smoke stain reflectance from the sample. It emits a steady light onto the smoke stain, which is reflected back from the smoke stain to a photosensitive element (Begum et al., 2004).
Table 2. Typical lower detection limits for EDXRF for filter.

\begin{tabular}{clc}
\hline Symbol & Name & LLD $(\mu \mathrm{g} / \mathrm{g})$ \\
\hline $\mathrm{S}$ & Sulfur & 10 \\
$\mathrm{Cu}$ & Copper & 0.9 \\
$\mathrm{Zn}$ & Zinc & 0.75 \\
$\mathrm{As}$ & Arsenic & 0.8 \\
$\mathrm{Se}$ & Selenium & 0.7 \\
$\mathrm{Cd}$ & Cadmium & 8 \\
$\mathrm{Hg}$ & Mercury & 2 \\
$\mathrm{~Pb}$ & Lead & 2 \\
\hline
\end{tabular}

The calibration of this equipment according to the appropriate instructions was done using a blank filter from the same batch as the exposed ones. The values were obtained using each piece (coarse and fine) of filter loaded on the SFU. The concentrations are operationally defined based on the amount of reflected light absorbed by the filter sample and an assumed mass absorption coefficient.

Secondly, the Energy Dispersive X ray Fluorescence (EDXRF) spectrometry was used to identify the element composition. An ARL Quant'X- EDXRFAnalyzer (Thermo Scientific, ARL Quant'X EDXRF analyzer) was used for spectral data acquisition and storage after a calibration using some specific sources. Both the coarse and the fine loaded filters from the Gent SFU were irradiated using ${ }^{45} \mathrm{Rh}$ source with 300 seconds live time to give reasonable statistical accuracy. The sampled filters were placed on the sample holder such that the loaded side faced the source of radiation as mentioned on the recommended method. The elemental composition from both filters was evaluated in consideration of the following elements with the lower limit detection (LLD) of the EDXRF on Table 2.

\section{RESULTS AND DISCUSSION}

There are relatively limited measurements; concentration of black carbon and some elements on the 
Table 3. Black carbon coarse concentrations on different location.

\begin{tabular}{lcccc}
\hline \multicolumn{1}{c}{ Coarse } & City Council & Sonel & Omnisport & Sopecam \\
\hline Means concentration $\left(\mu \mathrm{g} / \mathrm{m}^{3}\right)$ & 16.07 & 14.23 & 12.43 & 12.7 \\
S.D. & 0.68 & 1.33 & 1.89 & 2.20 \\
\hline
\end{tabular}

Table 4. Black carbon fine concentrations on different location.

\begin{tabular}{lcccc}
\hline \multicolumn{1}{c}{ Fine } & City Council & Sonel & Omnisport & Sopecam \\
\hline Concentration $\left(\mu \mathrm{g} / \mathrm{m}^{3}\right)$ & 12.32 & 9.33 & 9.2 & 11 \\
S.D. & 4.77 & 6.36 & 5.77 & 6.08 \\
\hline
\end{tabular}

coarse and fine filters at the four sampling site is presented below.

\section{1 Black Carbon}

The mean black carbon concentration measured at the four sites is given in Tables 3 and 4 . The absorption values can be converted into an estimated mass of black carbon using a value of the absorption efficiency. Some studies (Taha et al., 2007; Jeong et al., 2004) have shown that the blackness of the deposit depends on the location particularly with respect to distance to the traffic and emission sources.

On behalf of these tables, the location "City Council" records the highest mean concentration levels, 16.07 $\mu \mathrm{g} / \mathrm{m}^{3}$ for the coarse filter and $12.32 \mu \mathrm{g} / \mathrm{m}^{3}$ for the fine filter. The lowest mean concentration is recorded at the location "Omnisport". There is considerable variability in the concentration of black carbon across the locations.

The representation of these values (Fig. 2) shows the fluctuation of black carbon on the coarse and fine filter from one location to another.

Fig. 2 shows the distribution of mean concentration of black carbon for the coarse and fine filter in the four locations. We observe on this figure that the high value of the $\mathrm{PM}_{10}$ is $28.39 \mu \mathrm{g} / \mathrm{m}^{3}$; this value is superior to the WHO guidelines for $\mathrm{PM}_{10}$ (WHO guidelines, 2005). This report suggests $20 \mu \mathrm{g} / \mathrm{m}^{3}$ as standard for the annual average of $\mathrm{PM}_{10}$ and $10 \mu \mathrm{g} / \mathrm{m}^{3}$ for $\mathrm{PM}_{2.5}$. In this case, we note that the concentration of coarse black carbon is higher than the $\mathrm{PM}_{10}$ guideline at all the sampling sites and the concentration of fine black carbon is also higher than the $\mathrm{PM}_{2.5}$ guideline only at two sampling sites. We need to bring some appropriate resolution to reduce the emissions in order to attain the WHO guidelines for $\mathrm{PM}_{10}$ and $\mathrm{PM}_{2.5}$.

We remark on Fig. 2 that the means concentration on coarse filter is naturally superior to the fine filter. These obtained values in the city of Yaoundé are very superior to the mean values obtained in Ghana, which ranged from $0-2 \mu \mathrm{g} / \mathrm{m}^{3}$ (Kwame Aboh et al., 2007).

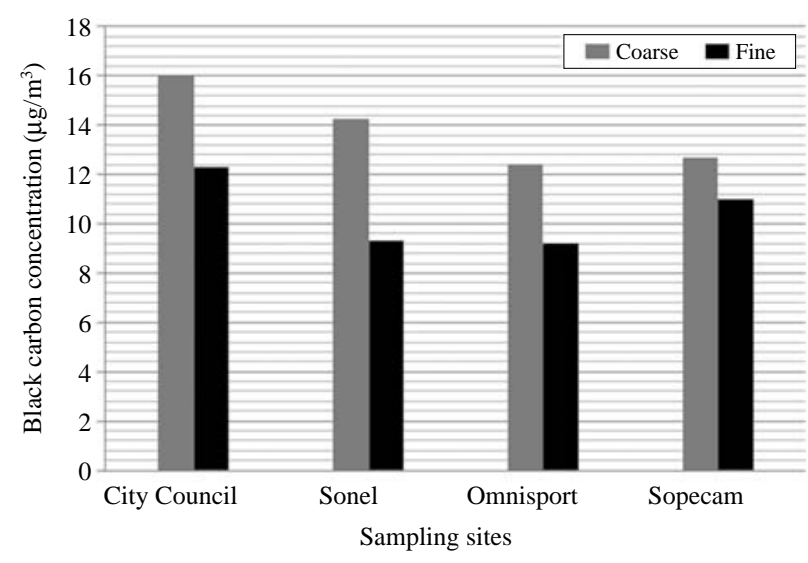

Fig. 2. Variation of Mean Black carbon concentration on coarse and fine filters.

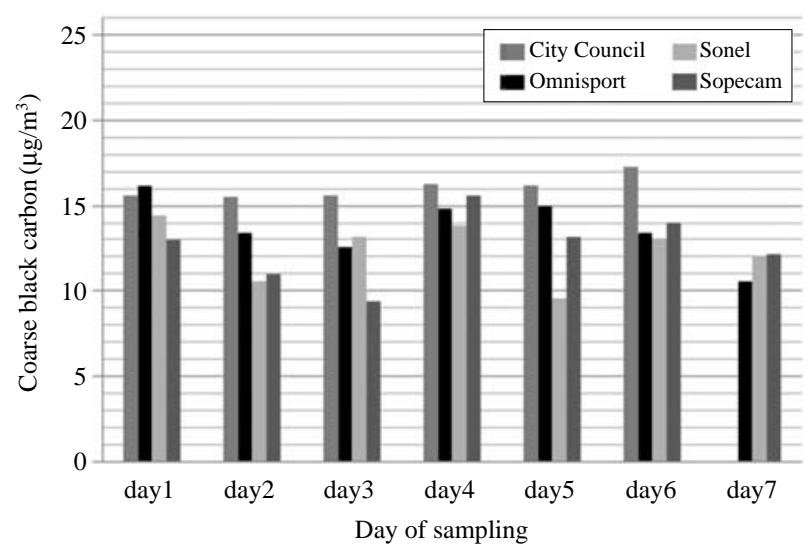

Fig. 3. Daily distribution of Black carbon concentration on coarse filter for the four locations.

The daily variations of the concentration of black carbon are presented for different locations in Fig. 3 for coarse samples and Fig. 4 for the fine samples.

On Fig. 3, we observe that the concentration peak is obtained on the day 6 at "City Council". It is impor- 


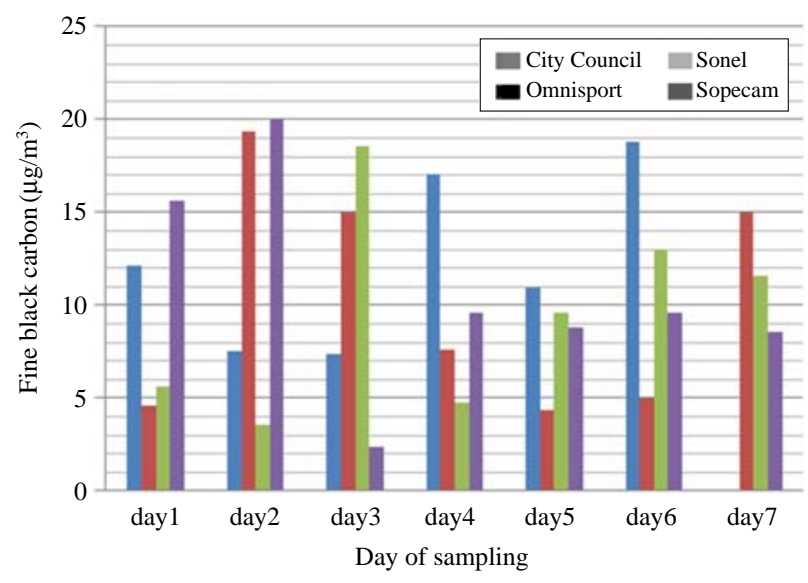

Fig. 4. Daily distribution of Black carbon concentration on fine filter for the four locations.

tant to mention that the sampling had not been done on the day 7 at this site.

The black carbon concentration peak obtained for the fine filter is at the location "Sopecam" on the day2. We observe on Figs. 3 and 4 that the maximum value of the day sampling is observed for the fine black carbon. Around this site, there is a big industry associated to an intense traffic. These deposited elements on the filter arise out of activities developed in some of these locations such as biomass burning, biofuels for cooking and the intense traffic on the ground not paved which created dust; it is clear that these emissions sources are link to the high fine black carbon concentration. The mean concentration is less than $25 \mu \mathrm{g} / \mathrm{m}^{3}$, which is a WHO guideline for $\mathrm{PM}_{2.5}$ on daily average.

\section{2 Elemental Composition}

Results for elemental concentrations analyzed by Energy Dispersive X-ray Fluorescence (EDXRF) spectrometry are discussed below. We have also considered the elements which have a strong potential for adverse public health effects.

Fig. 5 presents the spatial variation of the sum of element concentrations on the coarse and fine filter at four locations. We notice from this figure that concentrations for the coarse filter are higher than the fine filter. These suspended particle concentration exceed $20 \mu \mathrm{g} / \mathrm{m}^{3}$ for the coarse filter and $10 \mu \mathrm{g} / \mathrm{m}^{3}$ for the fine filter at some of the locations. On regard of the suspended particulate, air quality in the city of Yaoundé need to be followed and it is important to bring out some solutions to reduce the suspended particulate matter.

The highest summed concentrations of elements are observed at the location "Omnisport". In most of these locations, a greater influence of soil is the result of

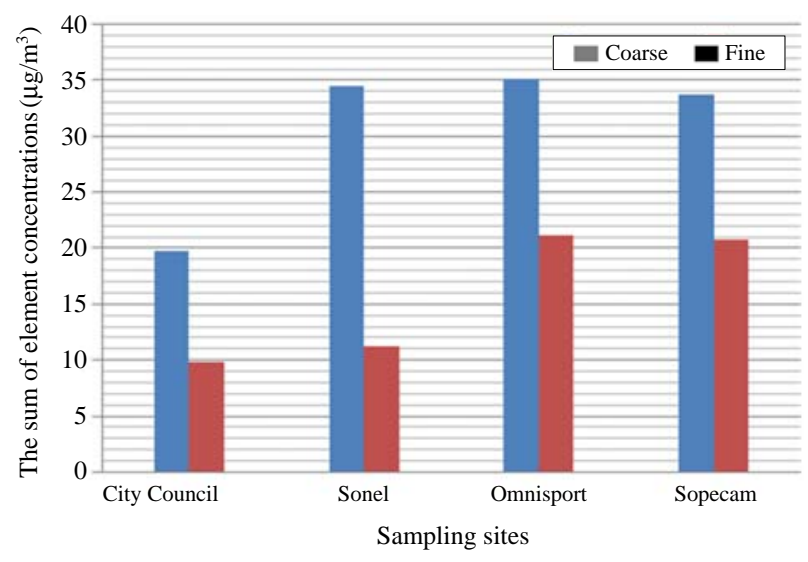

Fig. 5. Variation of the sum of element concentrations at different locations for coarse and fine filter.

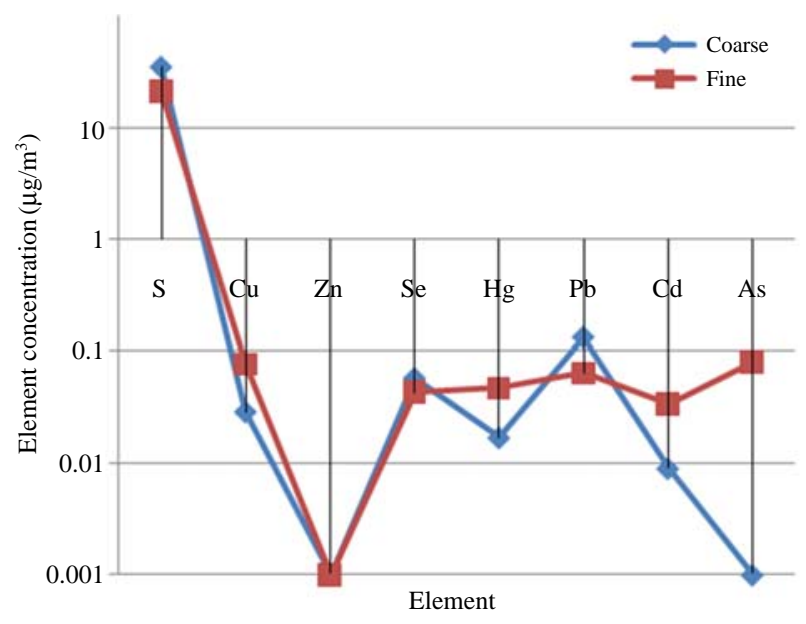

Fig. 6. Variation of coarse and fine element concentration at Omnisport.

frequent incursions of dust. To understand the presence of these elements for coarse and fine filter, we have represented the distribution for the location "Omnisport" (Fig. 6). In this figure, the concentration of these elements $\mathrm{S}, \mathrm{Cu}, \mathrm{Zn}, \mathrm{As}, \mathrm{Se}, \mathrm{Cd}, \mathrm{Hg}, \mathrm{Pb}$ are shown for the coarse and fine particles.

The representation of the others locations have similar variation, i.e., the sulfur mean concentration is high at all the four sites and others elements are less than 1 $\mu \mathrm{g} / \mathrm{m}^{3}$. In general, for the four locations, sulfur concentrations ranged between $14.7-31.4 \mu \mathrm{g} / \mathrm{m}^{3}, \mathrm{Cu}: 0.3-0.9$ $\mu \mathrm{g} / \mathrm{m}^{3}$, Zn: $2.7-4.4 \mu \mathrm{g} / \mathrm{m}^{3}$, As: $0-0.05 \mu \mathrm{g} / \mathrm{m}^{3}$, Se: $0-0.094$ $\mu \mathrm{g} / \mathrm{m}^{3}$, Cd: $0-0.53 \mu \mathrm{g} / \mathrm{m}^{3}, \mathrm{Hg}: 0-0.24 \mu \mathrm{g} / \mathrm{m}^{3}, \mathrm{~Pb}: 0-0.36$ $\mu \mathrm{g} / \mathrm{m}^{3}$. Some of these results are high compared to some studies carried out in Kenya such as $\mathrm{Zn}$ reaching $0.14 \mu \mathrm{g} / \mathrm{m}^{3}$ (Kinyua et al., 2008). The elemental composition, particularly with metallic elements has an 


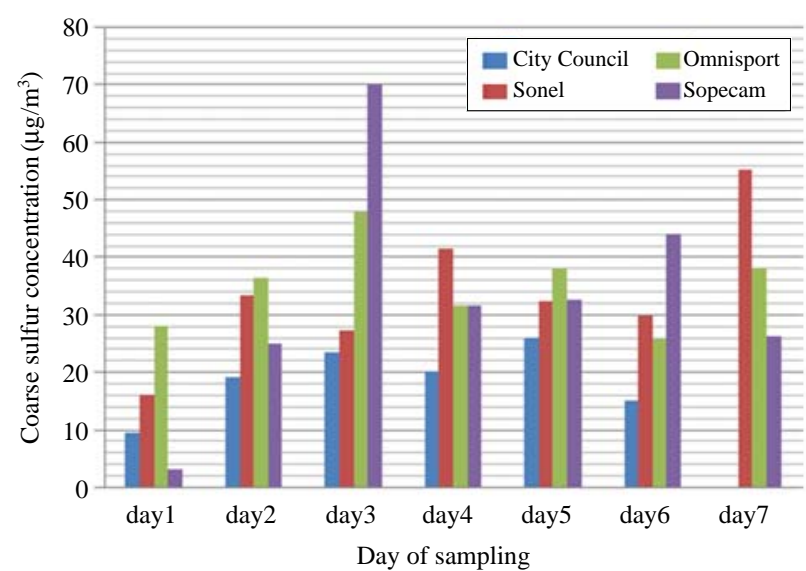

Fig. 7. Variation of coarse sulfur concentration on different locations.

impact on human health.

This study demonstrates that the spatial distributions of elemental components are highly heterogeneous; thus there is a potential exposure. The element sulfur has the highest concentration in the four locations, followed by lead and zinc. We have decided to represent the daily variation of these elements for the coarse and the fine filter on different location; also to present a relation between these elements and some emissions sources near the sites.

\subsubsection{Sulfur}

The analysis of different filters shows that the proportion of sulfur is major. The presence of this particulate matter depends strongly on the nature of local and the prevailing meteorological conditions. The treatment of the daily data gives the peak concentration and the location. The importance of this study is to ensure that there exists a link between a local emission source and the element.

Fig. 7 presents the daily distribution of the coarse sulfur concentration on different location. We can note that the location "Sopecam" obtains the highest value of coarse sulfur on the third day of sampling. This location has recorded also the lowest value of the coarse sulfur concentration. Around the sampling site, a smelting industry is present and this industry ejects sulfur in the form of gas $\left(\mathrm{SO}_{2}\right)$. The emissions are directly link to the activity of the industry. The conversion of gas produce fine particle, which can be transported over long distances. Thus, it is important to know the distribution of the fine sulfur for the four locations.

Fig. 8 is the distribution of fine sulfur on different locations. This figure confirms exactly the abundance of the fine sulfur on the location "Sopecam". The high-

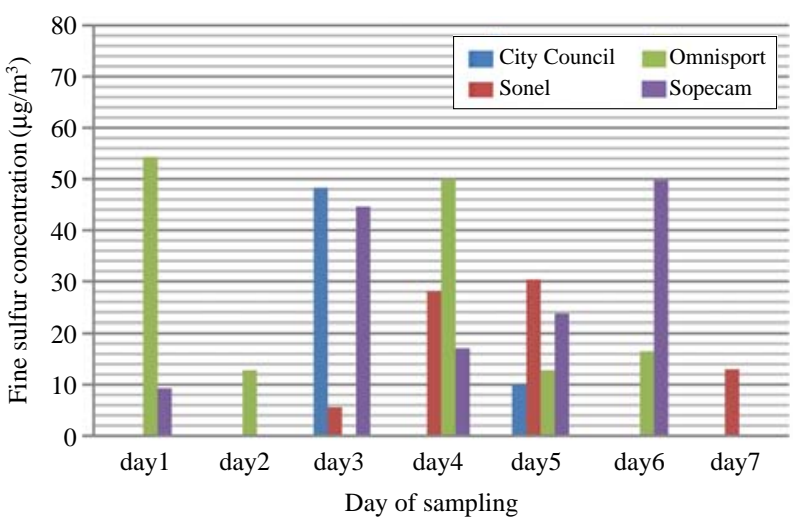

Fig. 8. Variation of fine sulfur concentration on different locations.

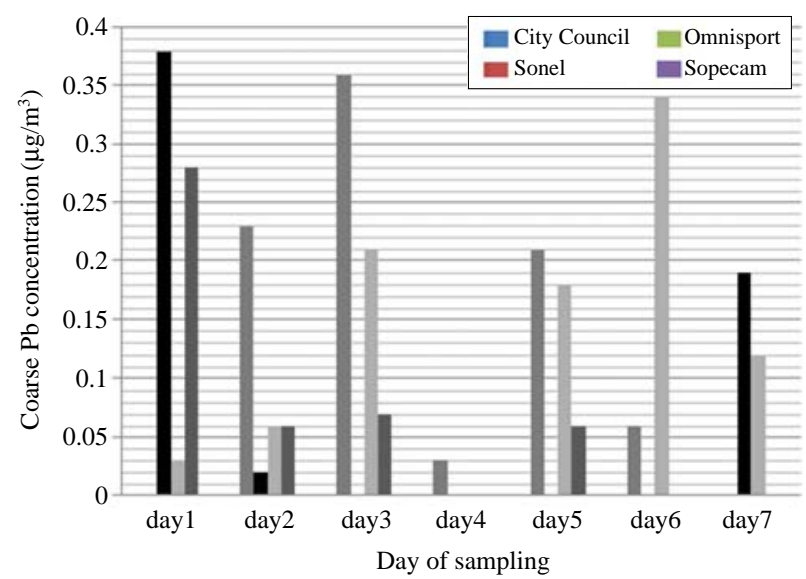

Fig. 9. Variation of coarse lead concentration on different locations.

est value is recorded at the location "Omnisport". We can explain this value by the displacement from the source to another location. These values are very high, compared to the value obtained in Kenyan city ranging between $0-7 \mu \mathrm{g} / \mathrm{m}^{3}$ (Kinyua et al., 2008).

\subsubsection{Lead}

In this study, lead is considered as an element with a great concentration. The obtained daily data is used to identify the location that has the high concentration and the emission sources.

Fig. 9 shows the distribution of coarse particulate lead at different locations. We note on this figure the fluctuation of lead concentration. The variation depends strictly on the location and the day where there is much traffic. The highest value is recorded on the location "Sonel". The others locations are recorded also a high value in regards of its toxicity.

In reference to some work, it has been reported a 


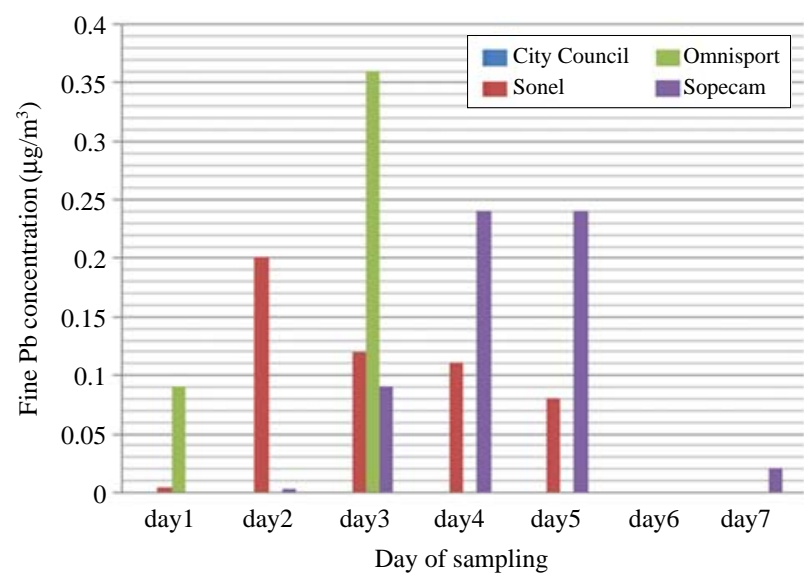

Fig. 10. Variation of fine lead concentration on different locations.

correlation between lead and motor vehicle emissions (Kinyua et al., 2008; Pinheiro et al., 2008). Considering the obtained results in this study, the assessment of the air quality must be carried out after any regulations on emission by old vehicles. We know that the organic compounds used in the fuel are the main factor of the contamination of road dust. Moreover, road dust suspended by the motion of the vehicle over the road surface can produce the fine particles. The distribution of fine lead concentration at the four sites is presented on Fig. 10.

The highest value of fine lead is recorded at the location "Omnisport". We remark on Fig. 10 that the fine lead is not present at the location "City Council". Although the concentration of the fine lead seems to be low, it is important to make a proposition to regulate the emission of fine particles.

\subsubsection{Zinc}

The impact on the environment of the mixture of oil and fuel used in some two-stroke motor vehicles to provide lubrication of piston in the cylinder is the deposit on the ground and these vehicles are the potential emission sources. The used oil contains additives that include zinc compounds and these compounds increase its lubricating capability. The zinc is released when the oil is burnt along with the fuel and is often observed as the white smoke coming from the engine exhaust from two-stroke motor vehicles (Hopke et al., 2008; Biswas et al., 2003).

The daily distribution of zinc at the four locations is showed on Fig. 11 for the coarse particle and Fig. 12 for the fine particle.

Compared to sulfur and lead at the four locations, the distribution of coarse and fine zinc is not regularly detected. We note that the highest value for the coarse

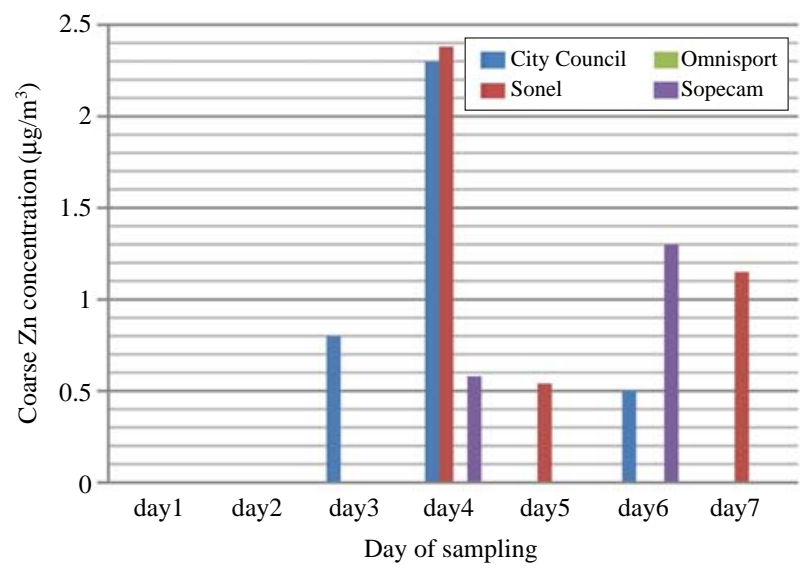

Fig. 11. Variation of coarse $\mathrm{Zn}$ concentration on different locations.

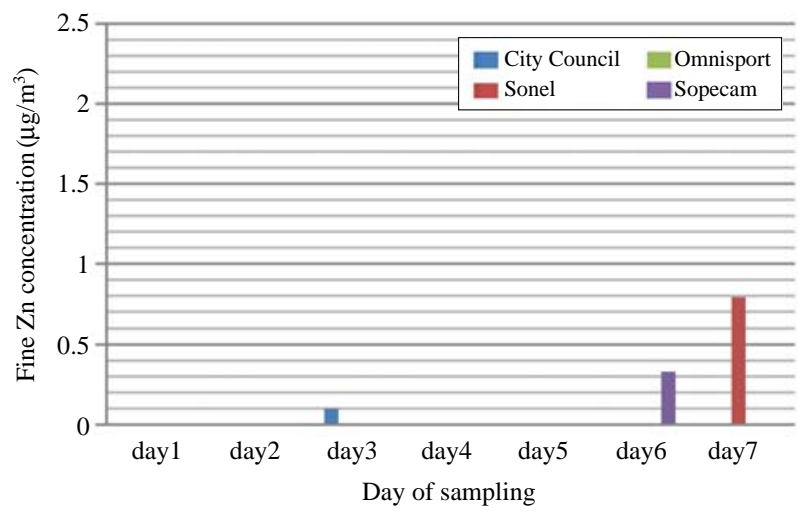

Fig. 12. Variation of fine $\mathrm{Zn}$ concentration on different locations.

zinc is recorded at City Council, while the highest value for the fine zinc is recorded at "Sonel". These locations, for which such data are available, are surrounded by solid waste. It has been reported in (Kinyua et al., 2008) that solid waste is an emission source of zinc in the environment.

However, the two-stroke emissions can provide zinc contributions to the urban street dust and thus, also can be found in the coarse fraction.

\section{CONCLUSIONS}

It has been shown that the reflectometer and the EDXRF are well suited for the analysis of filter due to its multi elemental capability, low detection limits for many element and due to its potential for accuracy. The results of this study indicate the elemental composition of particulate matter in the atmosphere. 
This study confirms the presence of pollutants in the atmosphere. Most of pollutants determined in this work were black carbon, sulfur, lead and zinc where the concentrations obtained on different locations for fine and coarse filter seem to be heterogeneous, non regular and high compared to some international values. To allow substantial decreases of species emissions in the future, it is important to:

- improve the quality of road in the city; so that there may be less dust. It would be necessary to accompany through aggressive control of road dust by street sweeping and related activities.

- include new fuel additives and alternate fuels.

- reduce the number of old vehicles and two-stroke motors in the city.

- collect and manage the solid waste in the city.

The results obtained from this work show that the value of $\mathrm{PM}_{10}$ is not attained at the four sampling sites just as recommended by WHO guidelines, but the black carbon concentrations of fine particulate exceeded the WHO guidelines for $\mathrm{PM}_{2.5}$ at two of the four sites. These values are greater than Kenyan values.

In some locations, some sources such as combustion of wood, biomass fuels and industrial activity lead to high concentrations of black carbon and sulfur. This implies that protection of population living in the neighborhood of the four sampling sites may require special measures to bring the pollution levels down and will complete protection for every individual against all possible adverse health effects of particulate matter.

According to the results, increases in risk are apparent in the city if the emission regulation is not put in place and some appropriate decision of the government to limit the use of old vehicles in the city. The health effects will be very serious such as cardiovascular, lung cancer and epidemiologic diseases in the case where any consideration is not done. Some works based on epidemiologic studies has suggested that the fine particle were more directly related to observed adverse health effects.

With the promulgation of the fine particulate matter for air quality standards, it is mentioned that the designated nonattainment areas may need to reduce emission of fine particles and their precursors to permit those areas to attain the ambient air quality standard. Development of efficient air quality management strategies requires knowledge of the sources that contribute to the problem and quantitatively apportion those contributions. This will be done if extensive efforts by some financial agencies contribute to have a continual sampling of particle in several locations, and more accuracy would be needed to appreciate the currently high concentrations elements seen across a city.

\section{ACKNOWLEDGEMENT}

This work was performed with the support of the public fund (budget 2010 of Cameroon) and the International Atomic Energy Agency (IAEA).

\section{REFERENCES}

Begum, B.A., Kim, E., Biswas, S.K., Hopke, P.K. (2004) Investigation of sources of atmospheric aerosol at urban and semi urban areas in Bangladesh. Atmospheric Environment 38, 3025-3038.

Biswas, S.K., Tarafdar, S.A., Islam, A., Khaliquzzaman, M., Tervahattu, H., Kupiainen, K. (2003) Impact of unleaded gasoline introduction on the concentration of lead in the air of Dhaka, Bangladesh. Journal of the Air \& Waste Management Association 53, 1355-1362.

Chai, Z., Qian, Q., Feng, X., Zhang, P., Liu, N., Feng, W., Kuang, M., Wang, H., Zhang, Y.(2008) A study on environmental pollution monitoring and occupational health in the capital iron and steel company, Beijing, china, using nuclear and related analytical techniques. IAEA-TECDOC-1576, 41-57.

Gatebe, C.K., Kinyua, A.M., Mangala, M.J., Kwach, R., Njau, L.N., Mukwolwe, E.A., Maina, D.M. (1996) The determination of suspended particulate matter of major significance to human health using Nuclear Techniques in Kenya. Journal of Radioanalytical and Nuclear Chemistry 203(1), 125-134.

Hopke, P.K., Cohen, D.D., Begum, B.A., Biswas, S.K., Ni, B., Pandit, G.G., Muhayatun, S., Chung, Y.S., Perry, D., Markwitz, A., Waheed, S., Siddique, N., Santos, F.L., Pabroa, P.C., Manikkuwadura, C.S., Wanna, W., Supamatthree, B., Vuong, T.B., Hien, P.D., Markowicz, A. (2008) Urban air quality in the asian region. Science of the Total Environment 404103-404112.

Hopke, P.K., Xie, Y., Raunemaa, T., Biegalski, S., Landsberger, S., Maenhaut, W., Artazo, P., Cohen, D. (1997) Charaterization of the gent stacked unit $\mathrm{PM}_{10}$ sampler. Aerosol Science and Technology 27, 726-735.

International Atomic Energy Agency (IAEA) IAEA TECDOC (1996) Operation guide on sampling, storage and sample preparation procedures for XRF analysis of environmental samples 45-46.

Jeong, C.H., Hopke, P.K., Kim, E., Lee, D.W. (2004) The comparison between thermal-optical transmittance elemental carbon and aethalometer black carbon measured at multiple monitoring sites. Atmospheric Environment 38, 5193-5204.

Kinyua, A.M., Gatebe, C.K., Mangala, M.J., Maina, D.M., Korrir, K., Odhiambo, G.O., Nderitu, S.K., Musyimi, P., Njogu, J., Bartilol, S., Mugera, W.G., Kamau, G.N., Hashim, N.O., Rathore, I.V.S, Stangl, R.L., Njue, W., Oyugi, M.P., Chhabra, S.C., Chakaya, J.M, Karama, M., Miungu, D.M., Kwach, R., Njau, L.N., Mukolwe, E.A. 
(2008) Monitoring of airbone particulate matter (APM), Backgroung radiation, analysis of trace metals and other parameters in some parts of Kenya; IAEA-TECDOC1576, 151-164.

Kwame Aboh I. J., Francis G. Ofosu (2007) Aerosol particles in a semi-urban area in Ghana RAF4/019 presentation.

Liu, X., Hopke, P.K., Cohen, D., Bailey, G. (1995) Sources of fine particle lead bromine, and elemental carbon in southeastern Australia. The Science of the Total Environment 175, 65-73.

Lyapunov, S.M., Frontasyeva, M.V. (2008) Workplace monitoring and occupational health studies at the centre for the production of phosphorus mineral fertilizers, voskresensk (Moscow region, Russian federation), using nuclear and related analytical techniques. IAEATECDOC-1576, 183-199.

Pinheiro, T., Bugaldo de almedia, A., Monteiro, P., Alvarez, E., Moniz, D., Alves, L.C., Freitas, M.C. (2008) Parti- culate matter and health- from air to human lungs. IAEATECDOC-1576, 165-182.

Taha, G., Box, G.P., Cohen, D.D., Stelcer, E. (2007) Black carbon measurement using laser integrated plate method. Aerosol Science and Technology 41, 226-276.

WHO air quality guidelines for particulate matter, ozone, nitrogen dioxide and sulfur dioxide; Global update, 2005. Summary of risk assessment;WHO/SDE/PHE/ $\mathrm{OEH} / 06.02$.

Wichmann, H.E., Spix, C., Tuch, T., Wichmann, H.E., Spix, C., Tuch, T., Wölke, G., Peters, A., Heinrich, J., Kreyling, W.G., Heyder, J. (2000) Daily mortality and fine and ultrafine particles in Erfurt, Germany. I. Role of particle number and particle mass. Cambridge (MA): Health Effects Institute.

(Received 18 July 2012, revised 30 April 2013, accepted 15 May 2013) 